Published in final edited form as:

J Nurs Scholarsh. 2005 ; 37(3): 289-293.

\title{
Developing a Scholarship Community
}

\author{
Sharon Cumbie, Clarann Weinert, Susan Luparell, Virginia Conley, and James Smith \\ Sharon Cumbie RN, PhD, CS, Alpha Phi, Assistant Professor, Fay W. Whitney School of Nursing, \\ University of Wyoming, Laramie, WY, Clarann Weinert SC, RN, PhD, FAAN, Zeta Upsilon, \\ Professor, College of Nursing, Montana State University-Bozeman, MT, Susan Luparell PhD, \\ APRN, BC, CCRN, Zeta Upsilon, Assistant Professor, College of Nursing, Montana State University, \\ Great Falls Campus, Great Falls, MT, Virginia Conley PhD, FNP, Associate Professor, Fay Whitney \\ School of Nursing, Laramie, James Smith MSW, PhD, Assistant Professor, Division of Social Work; \\ both at University of Wyoming, Laramie, WY
}

\section{Abstract}

Purpose-To report the results of a multidisciplinary, interinstitutional writing support group established to facilitate faculty scholarly productivity.

Organizing Concept-The road to scholarship can be filled with many obstacles, among them time constraints, teaching and meeting demands, student needs, office interruptions, and lack of colleagueship. The problems associated with lack of colleagueship, in particular, can be compounded for faculty who work in isolated contexts with few, if any, senior faculty to serve as mentors.

Methods of Development-The Western Writers Coercion Group evolved over a 2-year period from a small group of nursing faculty at a single institution to include, by its second year, 21 faculty from five western university campuses and three academic disciplines. The group met biweekly via teleconference with the objectives of defining and accomplishing realistic individual scholarship goals and providing a forum for the critical exchange of ideas.

Results-The ongoing support and mentoring of the group led to significant writing outcomes in the form of manuscripts submitted for publication, abstracts submitted for conference presentation, grant proposals developed, and collegial relationships formed.

Discussion-Although the benefits of group participation varied somewhat for faculty at different points in the career trajectory, they seemed to accrue at all levels of development. Group members underscored the many less quantifiable advantages of group participation: exposure to broader professional perspectives, the formation of key professional relationships, the enrichment of multidisciplinary input, and individualized assistance with time management, goal setting, and actual drafts.

Conclusions-The structure and experience of this group, which continues to meet regularly, might be a model to guide other groups of scholars who face geographic isolation and who struggle with balancing time and work and finding motivation for the process of writing.

\section{Keywords}

scholarship; community building; writing support group

The road to scholarship can be filled with many obstacles, among them time constraints, teaching and meeting demands, student needs, office interruptions, and lack of colleagueship. A common complaint related to knowledge dissemination is the absence of blocks of time to 
engage in writing and publication. For many would-be faculty scholars, these impediments to productivity compound, with days turning into weeks and weeks into months, and still manuscripts remain unfinished. The aim of the writing support group project, begun in the summer of 2002, was to create a structure and system to facilitate faculty scholarly productivity. The group evolved from an initially small group of nursing faculty at a single institution to a multidisciplinary and inter-institutional collaborative network for support, critique, mentoring, and scholarship development. In this article we will describe (a) the development, organization, and procedures of the writing group project; (b) group procedures and dynamics; (c) member productivity outcomes; (d) the evolution of the group's unique multidisciplinary and interinstitutional membership; (e) scholarship development experienced by members over geographic distances; and (f) the meaning of the group to its members.

\section{The Western Writers Coercion Group}

The initial and continuing goal of the Western Writers Coercion Group (WWCG) has been to facilitate faculty scholarly productivity through multidisciplinary and interinstitutional ongoing support, critique, mentoring, and scholarly exchange. The original writing support group project began in summer 2002 at the University of Wyoming (UW) School of Nursing. Its objectives were to create a collegial group to support scholarship development among faculty and to establish a forum for the critical exchange of ideas. Called the Scholarship Goals Group, its members focused on establishing and accomplishing realistic goals for their individual scholarly development. Members found the group successful and productive in several ways: Group interaction helped members learn to set realistic goals, critical feedback helped members develop and refine their scholarship, and the inherent pressure of having to "answer to" the group maximized member efforts to meet their goals. The group later named themselves the Wyoming Writers Coercion Group as a playful way to reinforce their commitment to the goals and work process that they had established.

Given the perceived success of the group's first year, faculty decided to reconvene during summer 2003, but to shift their focus toward the scholarship of writing and publication. As members discussed the group with colleagues at other institutions and in other disciplines, interest and enthusiasm grew. Nursing faculty came into the group, via teleconference, from Montana State University (MSU) and University of Nebraska (UN); and University of Wyoming faculty from the Division of Social Work (located on two campuses) and the Department of Mathematics joined their UW colleagues in nursing to create a multidisciplinary, interinstitutional project to promote scholarly development. Eventually, because of the expanded regional participation, the group was referred to as the Western Writers Coercion Group.

During the second year, as many as 21 faculty were members of the group, with an average of 10-12 participating at each meeting. The figure shows the three-state area involved in the project; the cumulative distance between the participating sites is 1187 miles (1912 kilometers).

The writing support group that continues to meet regularly, weekly or biweekly, remains comprised of members from five university campuses: UW, Laramie and Casper; UN, Scottsbluff; and MSU, Great Falls and Bozeman (see the Figure).

\section{Group Procedures and Dynamics}

WWCG meetings are conducted from UW's Nightingale Center for Nursing Scholarship (NCNS), through a teleconference connection supported by MSU's Center for Research on Chronic Health Conditions in Rural Dwellers (CRCHC). The NCNS (www.uwyo.edu/ncns/) coordinates the group's activities by collecting individual goals and disseminating them to the group via e-mail before the meetings, maintaining a record of group productivity, safeguarding 
the group's treasury, and making the necessary technical arrangements. The CRCHC (www.montana.edu/crchc/) maintains a web page for the group, which includes member information and photographs, and posts an ongoing report of member activity, including article and grant submissions, acceptances, and funding. The two centers have multiple links within each center's Web site to increase the visibility of the group's work and to facilitate access to collaborative relationships.

A description of basic group procedures will show the real, though good-natured application of pressure implied by the word "coercion" in the group's title. Members are encouraged to take ownership of their weekly or biweekly goals by investing in them literally as well as figuratively. For each upcoming meeting, participants submit a $\$ 5.00$ "filing fee" with the goals they have developed. Participants who fail to accomplish their goals "donate" their $\$ 5.00$ fees to the group's fund and must pay a new fee to file the next set of goals. Members who meet their weekly goals may apply their previous filing fees to their next submissions.

From the outset, the flow of the group's weekly meetings has varied naturally to meet the changing writing and professional needs of group members. As a result, no meeting progresses exactly like another. One part of every meeting, however, is the opportunity for each person to reflect on current goals, rethink future goals, and request group input or assistance.

Sometimes a writer asks for test readers for a current draft, in which case the group will try to recruit at least two volunteers. At other times, writers need input on the protocols of submission, publication, and review; and a discussion will ensue about topics such as when it is permissible to recontact an editor about a submission or how to interpret a request for revision and resubmission. Still other times, discussion moves outward to the larger world of scholarly writing: what is scholarship about, why is it important, why is it frequently so difficult. The essence of the meetings is that they evolve according to the needs of those participating.

Recently, group members have expressed interest in complementing the open, free-flowing discussion with some planned developmental or educational activities at selected meetings, for example, presentations by guest editors or writing experts. One immediate result is that plans are now underway to bring the editor of a major nursing publication electronically to the first group meeting of the spring semester.

\section{Member Productivity Outcomes}

The ongoing support and mentoring in the group has led to significant and positive writing outcomes in the form of manuscripts submitted for publication, abstracts submitted for conference presentations, grant proposals developed, and the formation of collegial relationships. Since June 2003, the beginning of the group's second year, 48 papers have been submitted for publication review, with 23 accepted thus far; and 6 grant applications have been completed, with 1 funded. These numbers continue to rise as review results come in and provide encouragement to group members.

\section{Overcoming Distance Barriers}

Other outcomes are less easily quantified, but are equally significant. One especially important benefit of the WWCG is the opportunity it provides members from geographically isolated campuses to connect and converse with colleagues across the distance. Teleconference meetings allow these far-flung group members to successfully overcome distance barriers and achieve significant collegial peer-group support.

In addition, several group members, although employed by large universities, are located on extended campuses and have few colleagues and limited resources to facilitate, support, and encourage scholarly pursuits. Two faculty, for example, are new researchers located 185 miles $(300 \mathrm{~km})$ from their main campus and their program's Office of Nursing Research; another 
two are located 473 miles $(766 \mathrm{~km})$ away from their main campus. Distance members report a sense of collegial support for scholarly activities, even though local resources and support might be less available. They also comment on the value of exposure to broader professional perspectives and experiences and the formation of key professional relationships that might not otherwise have had the opportunity to develop. Thus, by expanding the pool of colleagues available to provide scholarship support, WWCG members work toward counteracting the negative effects of isolation and the absence of senior, mentoring faculty that can present a serious challenge to career advancement in the contexts described.

\section{Interdisciplinary Enrichment}

Another key outcome of the writing group project stems from the group's interdisciplinary character. Because the WWCG provides an interprofessional forum for sharing and critiquing work from diverse disciplines (currently nursing, social work, and mathematics), collaboration would seem to require the ability to understand concepts and theories from other disciplines. During early meetings, group members questioned whether the predominance of faculty from one discipline (nursing) was a potential barrier to productive group interaction, whether a dominant paradigm might emerge and sabotage the openness of the process. From open discussion of this possibility, however, a consensus emerged that diversity of background would be enriching, a conclusion that experience has confirmed. It has been particularly true, for example, in regard to sharing manuscripts for critique. When members are ready for feedback on a draft, they announce that fact at a regular meeting or post an electronic file for e-mail distribution. In response to the request for reviewers, at least two or three members volunteer to read and critique the manuscript. The possibility for multidisciplinary perspectives here is especially valuable in that capable test readers from outside a discipline can provide a fresh reading of texts with which the authors might have become too familiar to be objective. Moreover, in somewhat a reversal of initial expectations, group members discovered considerable overlap and commonality in the value systems and expectations among disciplines that drew the writing community closer together.

\section{Meaning Across Career Trajectory}

One encouraging, and perhaps unexpected, outcome of the writing group's experience was its value to faculty with widely varied depth and breadth of experience in scholarship, publication, and grant writing. Although its membership comprised junior and senior-level faculty from various academic departments and in various geographic locations, the project began with a more or less implicit assumption that the group's main business would be to encourage professional development of the newer, less experienced members of the group. The extent to which this assumption underestimated the reach and influence of the group process became clear from the results of a year-end survey of the group to ask members to reflect on its meaning to them and their work.

Members of the WWCG were encouraged to complete a questionnaire that included data regarding their faculty rank and their employing institutions and departments and to indicate how participating in the writing group had facilitated their professional development and career goals. Fifteen of the 21 group members in 2003/2004, all with doctoral degrees, completed the questionnaires: 9 assistant professors, 4 associate professors, and 2 full professors. The assistant professors were the most varied group in experience and location. They had received their doctoral degrees between 7 and 56 months before completing the questionnaires, represented three different institutions and four campuses, and were in departments of nursing and social work. The four associate professors were less varied, coming from nursing or social work and representing two different institutions. The two professors were nursing faculty from different institutions and thus they were the most homogenous group. 
Regardless of the members' faculty status, stage of career development, department, or location, they found that group membership was meaningful to their scholarly development. However, as might be expected, members of the group assigned different meanings to their involvement in the writing group depending upon their stage of career development.

Assistant professors valued group membership for three reasons: (a) it provided an organizing structure for pursuing scholarship, (b) it gave valuable feedback on their manuscripts, and, most important, (c) it helped socialize them into their roles. The collegial relationships formed around a scholarly focus helped newer assistant professors understand that a fear of writing and submission for publication can be common and that the pursuit of scholarship is easily sidetracked by their many other faculty obligations. One assistant professor said of the group, "It provided mentorship to someone who was new to the academic/tenure process. It provided me encouragement and a sense of focus and motivation to write. It provided modeling for the 'how to' of writing and publishing." Another assistant professor from a satellite campus commented, "It is helpful to hear the language of research and writing and realize that others have trouble with time management also." Still another off-site member wrote:

[The group] gave me the structure within which I could establish realistic goals. As a part of that structure I formally "permit" myself to schedule time to think about my scholarly future - as a necessary part of my faculty role, rather than on my own as time permits. Participation in the group has also exposed me to "scholarly think." I work on a campus with just one other tenure-track faculty. Just being a part of discussions about how others explore goals, identify problems, and work through resolutions has been most beneficial. It validates that my own thought processes about scholarship and developing as a scholar are at least on track and, I believe, has had a tremendous influence on my socialization into the scholarly world.

More seasoned assistant professors facing the demands of upcoming tenure review wished the group had been available earlier in their careers because of the gentle coercion it exerts, the opportunity it provides to hone writing skills, and the supportive critique it facilitates.

The group's associate professors, who have already achieved tenure, found group membership meaningful because of the structure and motivation it provides and because of the sense of "interdisciplinarity" it fosters. One commented, "Participation provided me with structure to complete projects related to scholarship. Otherwise I put those on the "back burner."” Another wrote, "[The group] kept me focused even though I was unable to attend many meetings. ... I actually got one publication submitted and published." An associate professor of social work said, "The process of setting up the goals provided structure for my work. Also, working with the faculty on various papers helped increase my sense of interdisciplinarity." Finally, one offsite associate professor wrote, "Reading the work that is being done by others stimulated me to get moving and be productive. It is nice to be associated with a group whose focus is research. Though I was not able to attend the writing group meetings, just knowing that you exist was stimulating for me."

The two full professors who responded to the survey, like their group colleagues, valued the structure the writing group provided. However, they used the group less as a motivator for goal setting and attainment, as did their junior colleagues, than as a way to stay focused on and accountable to projects, due dates, and commitments and tracking goals they had already established. Both the simple process of writing down their goals and checking them off and their sense of responsibility to fellow group members helped them accomplish this. Furthermore, although they did not state it directly, their display of responsibility, as well as their expressed appreciation for the opportunity to read others' papers, shows that the professors might have derived further personal satisfaction and meaning from the opportunity to participate altruistically in the mentoring of the group's more junior members. 


\section{Summary Reflections}

Both the responses of WWCG group members to the group's second year of collaborative work and the collective productivity of the group in submissions, acceptances, and grants underscore the importance of collegial input and mentoring for faculty-particularly those in isolated locations with few support services-if they are to pursue successful scholarly careers. Moreover, the benefits of such collaborative relationships seem to accrue regardless of the group member's level of career development. All informants appreciated what membership in the group taught them about appropriate goal setting, time management, and the importance of structuring time to protect and privilege scholarly activities and output. All additionally believed that the opportunities for manuscript review from an interdisciplinary group were invaluable.

Beyond those commonalities, membership benefited and had meaning for faculty in differing ways depending upon their faculty status, stage of career development, and location. The different benefits and meanings described by group participants are consistent with those found in more formal academic peer-group mentoring relationships. In these relationships, experienced peers can serve a valuable role in mentoring newcomers, and such a relationship can contribute to the newcomers' successful socialization and improve their work performance (Allen, McManus, \& Russell, 1999). In academic contexts such as the ones in which WWCG members work, where more traditional types of one-on-one mentoring are frequently not available to faculty members, this writing support group was able to fulfill that much-needed role.

Members of the WWCG praised the general mentoring effect of the group and reported that their scholarly productivity was significantly enhanced through participation in it. This structure has the potential to provide guidance to other groups of scholars who face isolation from colleagues and who struggle with balancing time and work and finding motivation for the process of writing.

\section{References}

Allen T, McManus S, Russell J. Newcomer socialization and stress: Formal peer relationships as a source of support. Journal of Vocational Behavior 1999;54:453-470. 


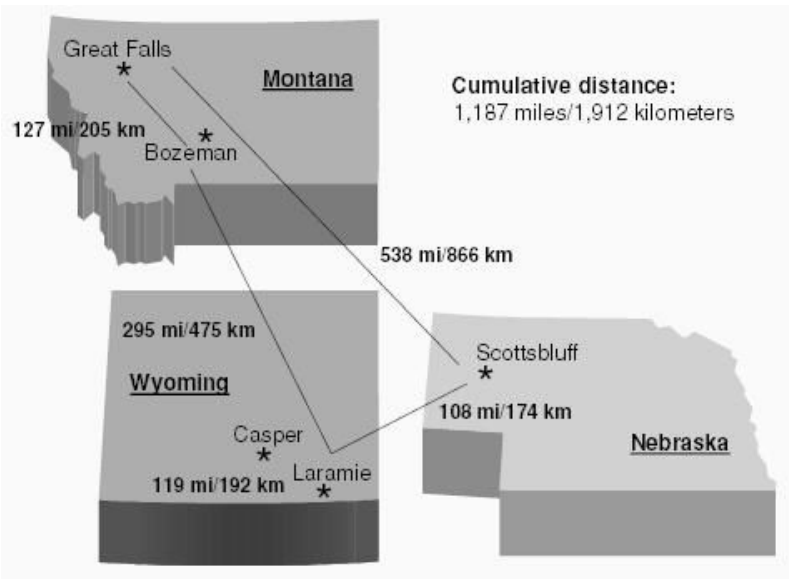

Figure.

During its second year, as many as 21 faculty were members of the group, with an average of 10 to 12 participating at each meeting. The figure shows the three-state area of the project; the cumulative distance between sites is 1,187 miles/1,912 kilometers. 